of these, homologous with the nephridia of other worms, such as Lumbricus, to which they are at all events suspiciously similar in arrangement and structure?

(3) What is the relationship of the large to the smaller nephridia? Are they modifications of the latter, or independent later developments ?

(4) In either case the Platyhelminth system must be more closely represented by the small nephridial bodies devoid of internal openings and provided with a network of ducts such as is found in Pirichata, Acanthodrilus, and Megascolides, than by the more specialized paired nephridia of such a form as Lumbricus.

Possibly the course of development as represented in living forms may be somewhat as follows :-

(I) A series of numerous nephridia present in each segment devoid of internal openings, and connected by a continuous network of ducts, as in Perichata.

(2) The aggregation of these smaller nephridia into tufts in various parts, as in the posterior region of Acanthodrilus; the subsequent. enlargement of certain of these nephridia and the acquirement by them of secondary internal openings. It is interesting to note in Megascolides that in the anterio part of the body, where the small nephridia are scattered over the whole body-wall of the segment, large nephridia are absent, whilst they are present in the posterior region, where the small nephridia are confined to a ring in the posterior part of the segment. In this case, as the nephridia become aggregated into tufts in the anterior part, the ducts connecting them with those in the posterior region of the segment next in front will become fewer, until when, as in Merascolides, only a single, modified, large nephridium remains on either side anteriorly, there will be simply one duct from seg. ment to segment uniting with a network of ducts in the region where the small nephridia still persist.

It is interesting to note that the aggregation of the smaller nephridia, and on this supposition the modification of certain of them to form the larger ones, commences in the posterior region of the body.

In certain worms, such as Acanthadrilus, the connection of the network of clucts from segment to segment seems to have b sen lost, at any rate in the adult: aggregation of these in the neighbourhood of the setæ, and subsequent modification, would give rise to a certain number of nephridia in each segment without any longitudinal duct.

(3) The next stage is reached in such a form as Lanice, where the longitudinal duct persists, but all trace of the smaller nephridia is lost.

(4) The final stage is present in most earthworms where, in the adult, all traces of both small nephridia and longitudinal duct are lost, though the latter is present, as in Lumbricus, during development.

These lead to three conclusions, two of which are practically dentical with those of $\mathrm{Mr}$. Beddard :-

(I) That the smaller nephridia without internal openings, irregularly scattered, and with a network of ducts such as are seen in Acunthodrilus, Perichata, and Megascolides, are homologous with the nephridial system of Platyhelminths.

(2) That the larger nephridia typical of most earthworms are secondary modifications of certain of the smaller ones subsequent to their aggregation into groups; the modified ones acquiring each an internal opening.

(3) That there is no homology between the longitudinal duct of Lumbricus, Lanice, Megascolides, \&c., with that of the Platyhelminths, since it has only been developed in the above forms in connection with the larger nephridia and as a modification of the original network, and has thus had its origin within the Chætopod group.

Melbourne University, May 3.

\section{Strange Rise of Wells in Rainless Season.}

MY attention has been directed to a letter published by you a few weeks ago (May 3I, p. 103) under the above heading. It would appear that there is something mysterious in the eyes of the author of the communication in question in the fact water in two wells at Fareham rose several feet in the month of March, as he states, "after a continuance of north-east wind, without rain, but with half a gale blowing"; so that it would appear that there was some connection between the north easterly gale and the rise of the water.
In this, however, the author is entirely mistaken; the rise of water in the wells in question is nothing more than the ordinary seasonable rise due to percolation. For twelve years past I have been carrying on constant observations of the underground water-supplies in various parts of this country, and it is quite true, as mentioned by the writer of the letter, that ordinarily the water in wells rises in the winter and falls in the summer; but this is by no means an exceptional rule, for in the present season there have been two low waters, the last of which occurred in the southern counties on the 8th of March in the present year. After that date 'commenced a very wet period, and before the end of the month over $2 \frac{1}{2}$ inches of rain had absolutely passed through the ground as measured by my percolation gauges The water in a well on the Surrey hills, which had been falling up to March 8, rose before the end of the month over 30 feet, which rise was entirely due to the replenishment from rainfall. I may point out that there are many wells at the present time in which the water is still rising, while in others in the same districts the water is falling, for the simple reason that as a rule underground water follows the same law as water fiowing in a river, and that the floods or high waters descend from the highest to the lowest districts, so that at present in wells situated in high positions the water is falling, while the crest of the wave of high water in the same watershed has not yet been reached in the lower levels of the district.

That the water in wells does fluctuate under certain conditions of the wind there is no doubt, as I have already drawn attention both to the fluctuations which take place in the water-levels of wells under barometric pressure and also in the volume of water discharged from the ground with a fall of the barometer. It should be noted that the rise of water in wells when due to barometric changes coincides with the fall of the barometer. Now a north-easterly wind as a rule is accompanied by a high barometer, and therefore is not likely to influence the rise of water in a well. During the month of March the rainfall was above the average, while there were comparatively few days with easterly winds, the only time when it could be termed a half-gale from the north-east occurring on the 19th of March, by which time the water in all the wells had made a consider able rise, due simply to ordinary percolation. Thus there is no mystery attaching to the rising of the water in these wells at Fareham. The rise simply took place from the replenishment of the springs, which this year occurred at a period somewhat different from ordinary years.

7 Westminster Chambers, Westminster, June $2 \mathrm{I}$.

\section{THE OPENING OF THE MARINE BIOLOGICAI \\ LABORATORY AT PLYMOUTH.}

THE Laboratory at Plymouth, which is now ready for work, is remarkable as being the first institution in this country designed purely for scientific research which has been originated and firmly established by the efforts of scientific men appealing to the generosity and confidence of wealthy individuals and corporations who desire the progress of knowledge for practical ends and the general good of the community.

It may be said that the Marine Biological Association will begin its active career on and after Saturday next. On that day Prof. Flower will, on behalf of the Association, declare that the Laboratory at Plymouth, which is now complete, is open for the purposes of biological research. The opening of the Laboratory may be said to mark an epoch in English zoological science, just as the opening of the Stazione Zoologica at Naples, which is essentially a German undertaking, marked an epoch in German science. It is true that small sea-side laboratories have already been established in the United Kingdom-at Granton, St. Andrews, and Liverpool Bay; but none of them can compare with the present undertaking in size and importance, and none can offer such advantages to the investigator.

The present institution, it may be remembered, is historically the outcome of the International Fisheries Exhibition held in London in 1883. That Exhibition served partly as an amusement to Londoners, but it also performed a far more important service-it directed 
people's minds towards the importance of our fisheries, and made them in some slight degree acquainted with the conditions under which those fisheries are worked. A.t the close of the Exhibition a large balance was left in the hands of its promoters, and it was hoped by many leading men of science that the money thus obtained would be utilized, in part at least, for the purpose of encouraging investigations upon the habits and economy of food-fishes. But the money was appropriated to other purposes, excellent in themselves, though useless as a means of promoting the welfare of the fishing industry. Prof. Lankester, however, nothing daunted by this want of success in obtaining funds from the surplus of the Fisheries Exhibition, and feeling that it was time to strike whilst people's minds were awakened to the importance of our fisheries and to the lack of scientific knowledge concerning them, determined to found an Association for the purpose of encouraging the study of the marine fauna of the British coasts, and with the consent and co-operation of the officers of the Royal Society called a meeting for this purpose in the rooms of the Society on March 3I, I884. The meeting was eminently successful. The Duke of Argyll proposed a resolution to found the Marine Biological Association of the United Kingdom, and was supported by the most eminent biologists in the country. An appeal was made for subscriptions in aid of the Association's projects, and was soon liberally responded to. His Royal Highness the Prince of Wales graciously consented to be patron of the Association, and gave liberally to its funds; the scientific Societies, the City Companies, the Universities, and finally Her Majesty's Government, joined the list of subscribers; and in a short time the Association was in a position to undertake the building of a laboratory. After some dicbate as to the most suitable locality for a laboratory, Plymouth was selected, partly because it is a large and important fishing port, partly because the richness of the marine fauna of the Sound and neighbouring shores was extolled by such eminent authorities as the late Dr. Gwyn Jeffreys, Mr. C. Spence Bate, and Prof. Charles Stewart. The Association was fortunate in securing a magnificent site for the Laboratory from the War Office. For this site, than which a better could not be found, the Association is greatly indebted to the Earl of Morley,

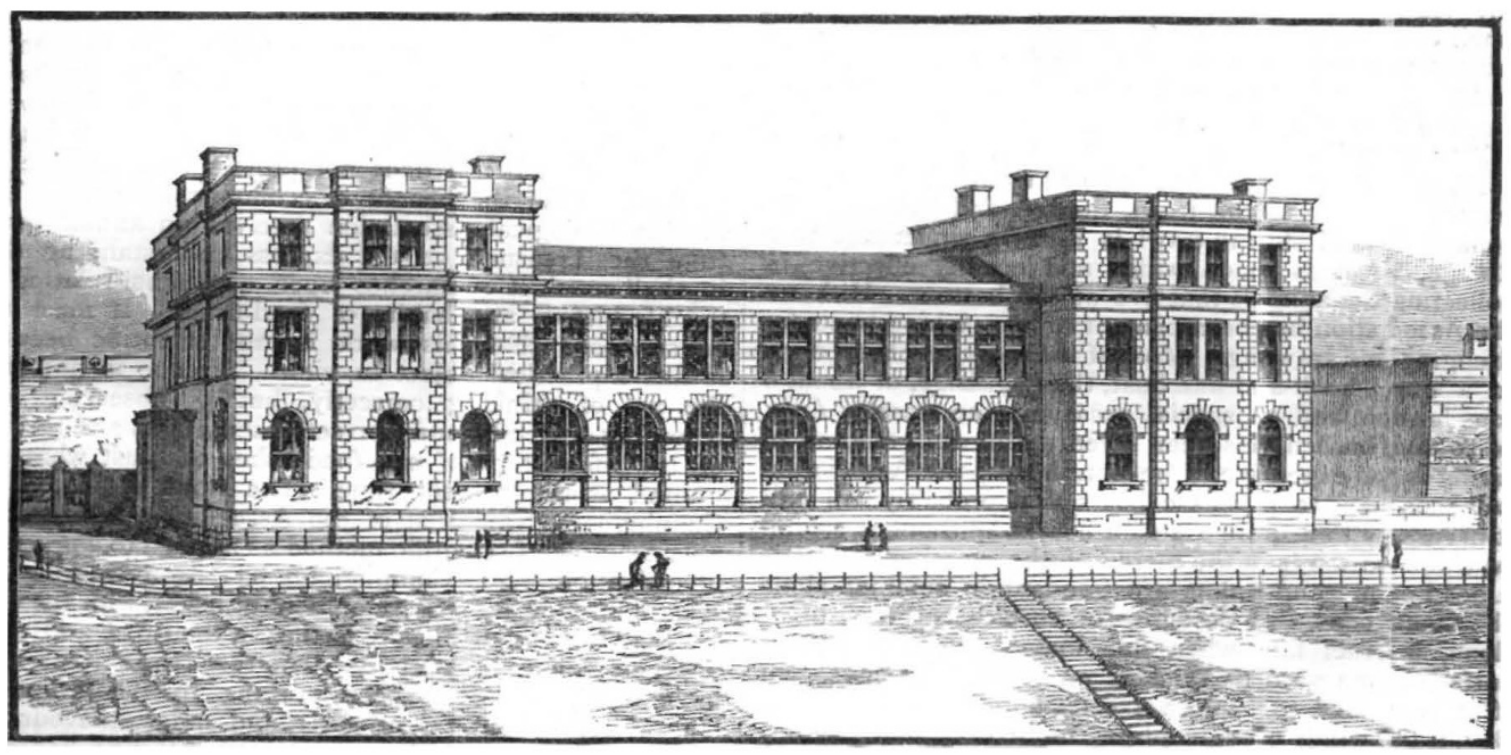

South Front of the Iaboratory of the Marine Biological Association, on the Citadel Hill, Piymouth.

then Under-Secretary of State for War, and to Sir Andrew Clarke, Inspector-General of Fortifications. The site granted is that part of the fosse of the Citadel lying to the south of the portion of the Citadel wall known as King Charles's Curtain ; it has a frontage towards the sea of 265 feet, and extends some 240 feet southwards of the Citadel.

The Laboratory which has been erected upon this site is admirably adapted to the purposes of the Association. It is, indeed, more than a laboratory, it is also an aquarium, whose tanks are extensive and fitted with every improvement that modern science can suggest. The total cost of building, machinery, and fittings, including all fees, has bcen about $£ \mathrm{I} 2,500$. The structure comprises a central portion with a wing at either end. The east wing is almost wholly taken up by the residence of the Director, and needs no further comment. The west wing has on the ground foor the caretaker's rooms, and a receiving-room into which the results of the day's fishing will be brought for examination. On the first floor are chemical and physiological laboratories, and on the second floor a library, a work-room, and lavatory. The main part of the building contains on the ground floor the aquarium or tank-room, and on the first floor the large laboratory. The tank-room is fitted with slate and glass tanks, of which one on the northern side is a noble window tank, 30 feet in length, 9 feet in breadth, and 5 feet deep. There are three large window tanks on the north side, nine smaller window tanks on the south side, and a series of five table tanks in the middle of the room. The tanks are supplied with salt water from two reservoirs, capable of holding 50,000 gallons each. From these the salt water is led by means of pumps through vulcanite pipes into the tanks; the openings of the pipes are placed rather more than a foot above the level of the water in the tanks, and are provided with nozzles through which the water is forced at high pressure, so as to form jets descending deep into the tank and carrying with them a quantity of atmospheric air. Circulation has been established in the tanks for the last fortnight, and there is every reason to be satisfied with the arrangements for aërating the water. The jets carrying down the air deep into the water of the tank cause it to be filled with minute bubbles so as to resemble champagne, 
and all the animals that have hitherto been placed in the tanks are thriving in a remarkable manner, which is the more surprising as new tanks are generally supposed to be highly injurious to organisms introduced into them at an early a date. It would be too much to expect that tanks which have been so lately put up should be fully stocked within a fortnight, nevertbeless they will present to the visitors on Saturday next a sufficiently interesting collection of local marine forms. For the rest the tankroom is a plain room, without any attempt at ornamentation. It is felt that the scientific nature of the institution must be kept in the foreground, and therefore nothing has been done to make the aquarium a place of popular amusement.

The main laboratory is at present fitted with seven compartments, each to contain a single naturalist, along its north side. When the necessity arises, similar compartments will be placed along the south side. In the centre of the room is a series of slate and glass tanks supplied with salt water from the circulating pumps. Beneath these a convenient shelf has been arranged, so that naturalists will be able to arrange for themselves any temporary apparatus that they may devise on as small a scale as is desired. All the arrangements for laboratory work will be completed at the end of the week, and the only thing now required is a company of ardent naturalists ready to undertake the work that lies to hand.

The material for work and for stocking the tanks is obtained from the Sound and the sea outside the breakwater by means of the trawl, dredge, and tow-net. In general a small shrimp-trawl is used in preference to a dredge, as it is much wider and equally effective in collecting the animals that live at the bottom. Hitherto the Association has been content to hire fishing-boats for dredging and trawling. Most of the work has been done in a small hook-and-line boat, the Quickstep, of about 6 tons burden, and on special occasions the trawler Lola, of 50 tons burden, has been hired. But this method of hiring is too expensive to be continued; the Association will soon have to purchase boats, and probably will find it necessary to acquire a steam-boat. Without a steamboat the station is at the mercy of the weather. If it is a dead calm-and calms are frequent in summer along the south coast-no dredging or surface netting can be done, a cruel fate when one knows that the pelagic surface fauna swarms thickest on bright calm days. Or if it is wished to explore a certain region on a certain day, if the winds prove contrary more than half the day is lost in beating up to the station; in any case one may generally expect to have a contrary wind on either the outward or the homeward journey. Such losses of time and material are most prejudicial to an institution like the Marine Biological Association. A steamlaunch has been found necessary at all other marine stations. Dr. Dohrn has two, the Johannes Müller and the Francis Balfour, at Naples ; and the Granton. Station is well provided for by the steam-yacht Medusa. But the funds of the Association have been well nigh exhausted in the building of the Laboratory. If a steam-launch is found requisite, it will be necessary to make another appeal to its friends, which, let it be hoped, will be as heartily responded $t s$ as the first appeal for funds for building the Laboratory.

It was stated in the early part of this article that the Association would begin its active existence on the 3oth. It would have been more proper to say its active public existence, for its staff has been active for some time past: Under the guidance of Mr. W. Heape, the late Superintendent, a careful though necessarily incomplete exploration of the Sound has been made, and numbers of animals have been identified, preserved, and put aside for future reference. Mr. Heape has also drawn up a complete list of the fauna and flora of the Sound, as recorded up to the present date, and a very formidable list it is. ${ }^{1}$ Botanists will note that there are more than 250 species of marine Algæ recorded from the neighbourhood, and some of them are extremely rare. Zoologists will see that there is an unlimited field in certain groups, particularly in the Crustacea and the Mollusca, but that some of the most interesting forms, the "pets of the laboratory," such as Amphioxus and Balanoglossus, are absent. But to say that they are absent means only that other less familiar forms are present, and that these old favourites have not been recorded. A good authority states that Amphioxus can be found in the immediate neighbourhood, whilst it is confidently expected that both Balanoglossus and Amphioxus can be introduced from the Channel Isles, and kept aliv 2 in the tanks. The zoologist need not fear that he will lie hindered by the poverty of the fauna; there is material enough and to spare. The remarkable Hydroid, Myriothela, occurs at low-tide mark in considerable quantities. The interesting Actiniæ, Edwardsia and Peachia, are to be found. Appendiculariæ and Sagittæ are taken in hundreds in the tow-net. Antedon rosaceus is abundant a quarter of a mile from the Laboratory, and mag. nificent specimens of Pinna wili attract the interest of the malacologist.

Such an institution as that at Plymouth challenges comparison with Dr. Dohrn's famous zoological station at Naples. But there is this remarkable difference between them. The Naples Station was founded for purely scientific objects: it does not profess to undertake investigations for the benefit of economic interests. The Marine Biological Association receives an annual grant from the Treasury, on the express understanding that it shall conduct researches upon questions relating to the life-history and habits of food-fishes. It must not be supposed that this work is not scientific because it has a practical object in view. Science is not only the. art of thinking correctly, but of observing and recording correctly, and correct observations and records of the life-history of our food-fishes are just what are wanted at the present time. The work of Mr. J. T. Cunningham, Naturalist of the Association, is an admirable example of scientific method as applied to a practical investigation. Mr. Cunningham has been working for several months at the development of fishes, with the view of obtaining and artificially fertilizing their ova and rearing their young in captivity. His results are necessarily incomplete, as he has been working in a half-finished laboratory, without gas or water, and under unfavourable conditions as regards boats and men. But he has succeeded in tracing out the life-history of the "merry sole" (Pleuronectes microcephalus), and has acquainted himself with such important facts concerning the development of the common sole, that he confidently expects to be able to hatch out the young next season, his experiments this year having failed only for want of the proper apparatus. He has also recorded the interesting fact that the herring spawns continuously from January to June in the Channel, and appears to have no definite breeding-season as it has in northern waters; and has discovered important facts relative to the breeding of the mackerel, conger, and pilchard, which will be made public as soon as his researches are complete. He has now stocked one of the large tanks in the aquarium with conger, and hopes in a short time to give a final opinion on the obscure question of the breeding of this fish. Not less interesting than Mr. Cunningham's researches are those of Mr. Weldon on the breeding of the common lobster, and the rock-lobster or craw-fish (Palinurus). Another of the tanks in the aquarium is occupied by the "berried" females of these forms, whose bright colours and active movements are as attractive to the casual spectator as their study is interesting to the zoologist and fisherman. So much has been

${ }^{x}$ Mr. Heape's list will be published in the forthcoming number (No. II.) of the Journal of the Marine Biological Association. 
done already by Messrs. Cunningham and Weldon under the most unfavourable conditions that it cannot but be anticipated that when a number of investigators are working under favourable conditions on different groups, but with a common object in view, results of the greatest scientific and practical importance will accrue.

The ceremony on Saturday will be interesting and important. Many of the leading biologists in England will be present, but unfortunately the eminent President of the Association, Prof. Huxley, will be absent on account of ill-health, and so, unfortunately, will Prof. Moseley, one of its most ardent and generous supporters. The Fishmongers' Company have added to their munificent patronage of the institution by undertaking the entertainment of the numerous guests who have been invited to the ceremony ; and the Association will be launched on its career of usefulness in a manner worthy of its aspirations, and satisfactory in the highest degree to its energetic promoters.

G. C. B.

\section{PERSONAL IDENTIFICATION AND DESCRIPTION.}

\section{II.}

PER

ERSONAL characteristics exist in much more minute particulars than those described in the last article. Leaving aside microscopic peculiarities which are of unknown multitudes, such as might be studied in the $800,000,000$ specimens cut by a microtome, say of one two-thousandth part of an inch in thickness, and one tenth of an inch each way in area, out of the 4000 cubic inches or so of the flesh, fat, and bone of a single average human body, there are many that are visible with or without the aid of a lens.

The markings in the iris of the eye are of the above kind; they have been never adequately studied except by the makers of artificial eyes, who recognize thousands of varieties of them. These markings well deserve being photographed from life on an enlarged scale. I shall not dwell now upon these, nor on such peculiarities as those of hand-writing, nor on the bifurcations and interlacements of the superficial veins, nor on the shape and convolutions of the ear. These all admit of brief approximate description by the method explained in the last article-namely, by reference to the number in a standard collection of the specimen that shall not differ from it by more than a specified number of units of unlikeness. I fully explained what a unit of unlikeness was, and certain mechanical means by which a given set of measures could be compared with great ease and by a single movement with every set simultaneously, in a large standard collection of sets of measures.

Perhaps the most beautiful and characteristic of all superficial marks are the small furrows with the intervening ridges and their pores that are disposed in a singularly complex yet even order on the under surfaces of the hands and the feet. I do not now speak of the large wrinkles in which chiromantists delight, and which may be compared to the creases in an old coat or to the deep folds in the hide of a rhinoceros, but of the fine lines of which the buttered fingers of children are apt to stamp impressions on the margins of the books they handle, that leave little to be desired on the score of distinctness. These lines are found to take their origin from various centres, one of which lies in the under surface of each finger-tip. They proceed from their several centres in spirals and whorls, and distribute themselves in beautiful patterns over the whole palmar surface. A corresponding system covers the soles of the feet. The same lines appear with little modification in the hands and feet of monkeys. They appear to have been

I The substance of a Lecture given by Francis Galton, F.R.S., at the Royal Institution on Friday evening, May 25. 1888. Continued from p. 177. carefully studied for the first time by Purkinje in 1822 . since then they have attracted the notice of many writers and physiologists, the fullest and latest of whom is Kollman, who has published a pamphlet upon them, "Tastapparat der Hand" (Leipzig, 1883), in which their physiological significance is fully discussed. Into that part of the subject I am not going to enter here. It has occurred independently to many persons to propose finger-marks as a means of identification. In the last century, Bewick in one of the vignettes in the "History of Birds" gave a woodcut of his own thumbmark, which is the first clear impression that I know of. Some of the latest specimens that I have seen are by Mr. Gilbert Thomson, an officer of the American Geological Survey, who, being in Arizona, and having to make his orders for payment on a camp suttler, hit upon the expedient of using his own thumb-mark to serve the same purpose as the elaborate scroll engraved on blank cheques - namely, to make the alteration of figures written on it, impossible without detection. I possess copies of two of his cheques. A San Francisco photographer, Mr. Tabor, made enlarged photographs of the finger-marks of Chinese, and his proposal seems to have been seriously considered as a means of identifying Chinese immigrants. I may say that I can obtain no verification of a common statement that the method is in actual use in the prisons of China. The thumb-mark has been used there as elsewhere in attestation of deeds, much as a man might make an impression with a common seal, not his own, and say, "This is my act and deed"; but I cannot hear of any elaborate system of finger-marks having ever been employed in China for the identification of prisoners. It was, however, largely used in India, by Sir William Herschel, twenty-eight years ago, when he was an officer of the Bengal Civil Service. He found it to be most successful in preventing personation, and in putting an end to disputes about the authenticity of deeds. $\mathrm{He}$ described his method fully in NATURE, in I880 (vol. xxiii. p. 76), which should be referred to by the reader; also a paper by Mr. Faulds in the next volume. I may also refer to articles in the American journal Science, 1886 (vol. viii. pp. 166 and 212).

The question arises whether these finger-marks remain unaltered throughout the life of the same person. In reply to this, I am enabled to submit a most interesting piece of evidence, which thus far is unique, through the kindness of Sir Wm. Herschel. It consists of the imprints of the two first fingers of his own hand, made in 1860 and in 1888 respectively; that is, at periods separated by an interval of twenty-eight years. I have also two intermediate imprints, made by him in 1874 and in 1883 respectively. The imprints of 1860 and 1888 have now been photographed on an enlarged scale, direct upon the engraver's block, whence Figs. 9 and II are cut; these woodcuts may therefore be relied on as very correct representations. Fig. Io contains the portion of Fig. 9 to which I am about to draw attention. On first examining these and other finger-marks, the eye wanders and becomes confused, not knowing where to fix itself; the points shown in Fig. Io are those it should select. They are those at which each new furrow makes its first appearance. The furrows may originate in two principal ways, which are not always clearly distinguishable: (I) the new furrow may arise in the middle of a ridge ; (2) a single furrow may bifurcate and form a letter $Y$. The distinction between (I) and (2) is not greatly to be trusted, because one of the sides of the ridge in case ( $\mathrm{I}$ ) may become worn, or be narrow and low, and not always leave an imprint, thus converting it into case (2); conversely case (2) may be changed into (1). The position of the origin of the new furrow is, however, none the less defined. I have noted the furrow-heads and bifurcations of furrows in Fig. 9, and shown them separately in Fig. 10. The reader will be able 